\title{
KAPSIES: A program for the calculation of multi-step direct reaction cross sections
}

\author{
A.J. Koning ${ }^{a}$, J.M. Akkermans ${ }^{b}$ \\ ${ }^{a}$ Netherlands Energy Research Foundation ECN, P.O. Box 1, 1755 ZG Petten, The Netherlands \\ b University of Twente, Department of Computer Science, Information Systems Group, P.O. Box 217, 7500 AE Enschede, The Netherlands
}

Received 25 July 1994

\begin{abstract}
We present a program for the calculation of continuum cross sections, spectra, angular distributions and analyzing powers according to various quantum-mechanical theories for statistical multi-step direct nuclear reactions.
\end{abstract}

\section{PROGRAM SUMMARY}

Title of program: KAPSIES

Catalogue number: $\mathrm{ACVZ}$

Program obtainable from: CPC Program Library, Queen's University of Belfast, N. Ireland (see application form in this issue)

Licensing provisions: none

Computers: DEC-AXP, SUN-SPARC, CONVEX

Operating systems under which the program has been tested: UNIX

Programming language used: FORTRAN-77

No. of lines in distributed program, including test data, etc.: 1123 (KAPSIES1), 1790 (KAPSIES2), 38786 in total

Additional program required: ECIS88 (author: J. Raynal), obtainable from the NEA Data Bank [1]

Keywords: pre-equilibrium nuclear reactions, multi-step direct, continuum cross sections

\section{Nature of physical problem}

Multi-step direct (MSD) reaction theories provide a quantummechanical description of the intermediate, pre-equilibrium region between direct and compound nuclear reactions. Without exception, these theories are based on an extension of (discrete state) direct reaction concepts to the continuum part of the nuclear level scheme, where the high level density of the residual nucleus necessitates statistical postulates in order to obtain computationally tractable formulae for the analysis of these processes.

\section{Method of solution}

Multi-step direct cross sections and analyzing powers are calculated according to three different MSD models [2]. This is done by processing standard DWBA cross sections into energy averaged continuum cross sections according to different statistical prescriptions.

\section{Restrictions on the complexity of the problem}

The present program can be used for nucleon inelastic scattering with incident energies between 10 and at least $200 \mathrm{MeV}$.

Typical running time: About 1-5 minutes for a total run

\section{References}

[ 1 ]NEA Data Bank, OECD/Nuclear Energy Agency, 12 boulevard des Iles, 92130 Issy les Moulineaux, France.

[2]A.J. Koning and J.M. Akkermans, Phys. Rev. C 47 (1993) 724. 


\section{LONG WRITE-UP}

\section{Introduction}

When a nuclear reaction proceeds by the MSD mechanism, it is imagined that throughout the scattering process at least one particle is in the continuum and that at each subsequent step of the reaction a new particle-hole pair is created. After one or a few steps, the continuum particle is emitted in a direction that still has some correlation with the initial direction. This, together with the high density of states, explains the observed (energy averaged) smooth forward peaked angular distributions (for examples, see [1,2]). The MSD reaction mechanism provides a significant fraction of the total reaction cross section for incident nucleon energies between 10 and $200 \mathrm{MeV}$.

In [3], we have shown that the whole spectrum of current MSD models can be derived from distorted wave theory plus different statistical postulates, called leading-particle statistics and residual-system statistics, respectively. Residual-system statistics implies that there is a random configuration mixing of residual nuclear states, whereas leading-particle statistics assumes that the DWBA matrix elements for projectile interaction are randomly distributed. As a result, off-diagonal terms cancel and the cross section formulae are considerably simplified $[2,3]$.

This paper reports on the code system KAPSIES, which calculates nucleon inelastic cross sections to the continuum according to the MSD models of Feshbach, Kerman and Koonin (FKK) [4], Tamura, Udagawa and Lenske (TUL) [5] and an approximation to the Nishioka, Weidenmüller and Yoshida (NWY) model [6]. The relations between the various MSD theories are depicted in Fig. 1.

KAPSIES is the first system that allows to calculate all of these MSD models; only partial implementations currently exist $[7,8]$. In addition, all implemented models in KAPSIES employ the same set of parameters for the optical model, DWBA cross sections, level densities, etc. This enables one to carry out a comparison between different MSD theories on a consistent basis. Results of such calculations have been reported in [9-11].

For each MSD model, KAPSIES computes double-differential (and angle-integrated) cross sections and analyzing powers in the continuum for each individual step as well as for the total MSD cross section (i.e. summed over steps). This enables us to analyze a large part of the experimental energy spectrum and the associated angular distributions. As an additional test for the validity of the quantum-mechanical models, we have also implemented the systematics of Kalbach [12], a purely phenomenological approach based on data fitting that has become well known for its reliable estimates of continuum angular distributions. In [11] we have shown that the quantum-mechanical approaches implemented in KAPSIES perform comparable to or better than the systematics and generally predict the double-differential cross sections better than the semiclassical approaches such as the exciton model [1,13-15]. Given the present-day computer power, the quantum-mechanical approach to pre-equilibrium reactions is amenable for large-scale nuclear data applications.

We recapitulate the model equations that are implemented in KAPSIES in Section 2 and give a description of the code system and the method of calculation in Section 3. In Section 4, we discuss the implementation and some test results. Sample input and output for a typical run are given at the end of this paper.

\section{MSD model equations and data flow}

The expressions for the MSD cross section have been derived from statistical principles in [3] and subsequently transformed into a computable form in [11]. These cross sections have in common that they consist of a combination of state densities and DWBA cross sections. The particular form of this combination is a direct 


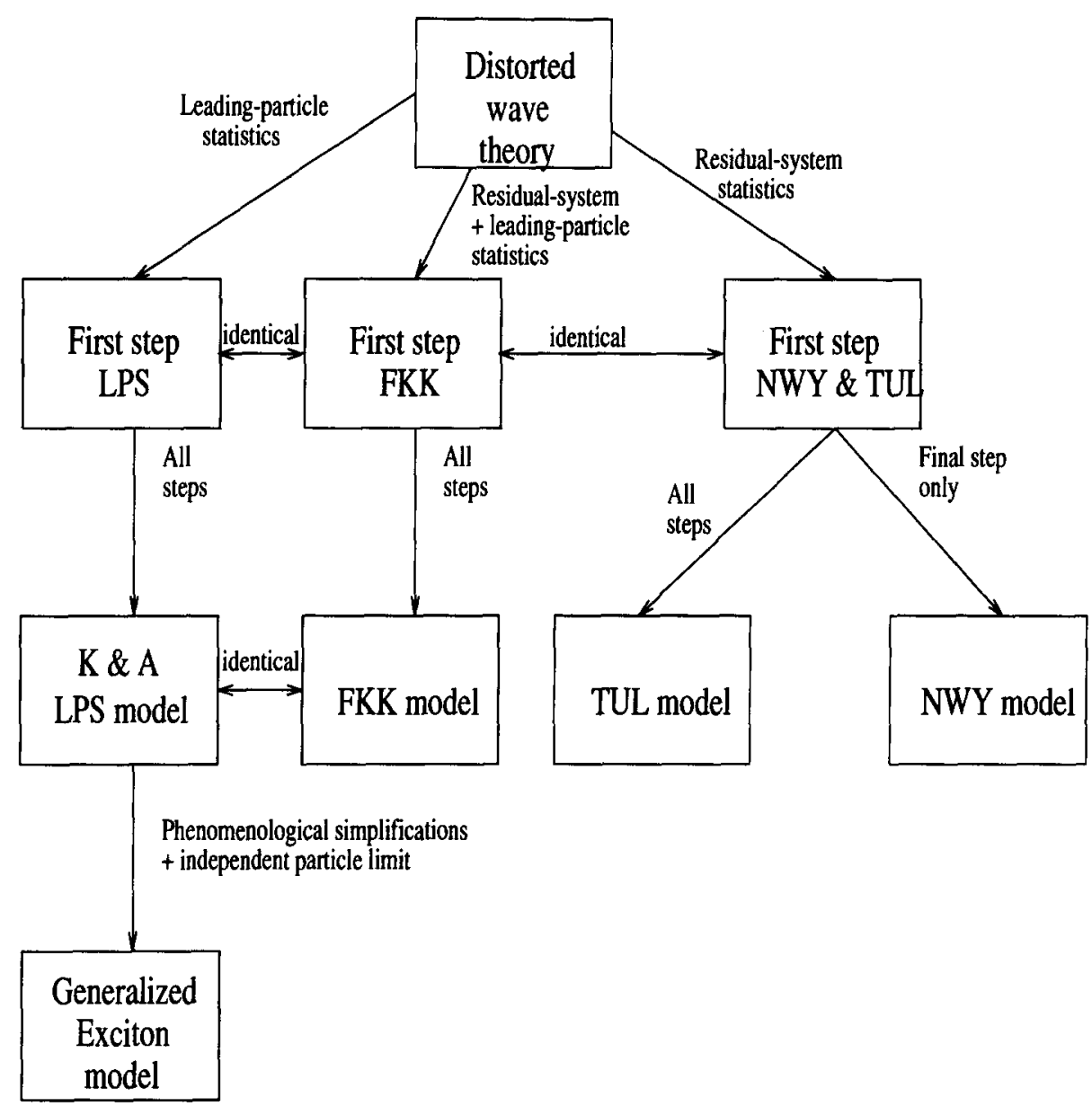

Fig. 1. Family tree of statistical MSD-theories. Here, LPS stands for leading-particle statistics, FKK for Feshbach, Kerman and Koonin [4], TUL for Tamura, Udagawa and Lenske [5], NWY for Nishioka, Weidenmüller and Yoshida [6] and K \& A for Koning and Akkermans $[3,11]$.

result of the statistical postulates that are associated with the various theories cited above. The continuum cross section can be written as an incoherent sum of one-step and multi-step cross sections:

$$
\frac{d^{2} \sigma\left(E, \Omega \leftarrow E_{0}, \Omega_{0}\right)}{d \Omega d E}=\sum_{n=1}^{\infty} \frac{d^{2} \sigma^{(n)}\left(E, \Omega \leftarrow E_{0}, \Omega_{0}\right)}{d \Omega d E}
$$

The one-step cross section is the same for all models, namely

$$
\frac{d^{2} \sigma^{(1)}\left(E, \Omega \leftarrow E_{0}, \Omega_{0}\right)}{d \Omega d E}=\sum_{l}(2 l+1) R(l) \omega_{1 p 1 h}\left(E_{0}-E\right)\left[\frac{d \sigma^{(1)}\left(E, \Omega \leftarrow E_{0}, \Omega_{0}\right)}{d \Omega}\right]_{l}^{D W B A} .
$$

We use the the Williams particle-hole state density $\omega_{p, h}$ for $p$ particles and $h$ holes with consideration of the finite depth of the hole $[16,17]$

$$
\omega_{p, h}\left(E_{x}\right)=\frac{g^{n}}{p ! h !(n-1) !} \sum_{j=0}^{h}(-1)^{j}\left(\begin{array}{l}
h \\
j
\end{array}\right)
$$




$$
\times\left(E_{x}-P-A_{p, h}-j F\right)^{n-1} \Theta\left(E_{x}-P-E_{P P}-j F\right),
$$

where $F$ is the Fermi energy, $g$ the single-particle state density, $E_{x}$ the excitation energy, $n=p+h$ the exciton number, $E_{P P}=\left[p^{2}+h^{2}+p-h\right] / 2 g$ the minimum energy required to excite $p$ particles and $h$ holes satisfying the Pauli principle, $A_{p, h}=[p(p-1)+h(h-1)] / 4$ the Pauli correction factor, $P$ the pairing correction and $\Theta$ denotes the unit step function. The spin distribution function $R(l)$ is given by

$$
R(l)=\frac{2 l+1}{2 \sqrt{2 \pi} \sigma^{3}} \exp \left[-\frac{\left(l+\frac{1}{2}\right)^{2}}{2 \sigma^{2}}\right],
$$

where $\sigma$ is the spin cutoff factor. The quantities in Eq. (2) between square brackets are DWBA cross sections, which we evaluate using a macroscopic vibrational model $[2,11]$.

Applying leading-particle statistics to the higher order distorted wave Born series yields the $n$-step cross section of the FKK model [4]:

$$
\begin{aligned}
\frac{d^{2} \sigma^{(n)}\left(E, \Omega \leftarrow E_{0}, \Omega_{0}\right)}{d \Omega d E}= & \frac{m}{4 \pi^{2} \hbar^{2}} \int \mathrm{d} \Omega_{n-1} \int \mathrm{d} E_{n-1} E_{n-1} \frac{d^{2} \sigma^{(1)}\left(E, \Omega \leftarrow E_{n-1}, \Omega_{n-1}\right)}{d \Omega d E} \\
& \times \frac{d^{2} \sigma^{(n-1)}\left(E_{n-1}, \Omega_{n-1} \leftarrow E_{0}, \Omega_{0}\right)}{d \Omega_{n-1} d E_{n-1}} .
\end{aligned}
$$

A salient feature of the convolution structure of this equation is that the $n$-step cross section can be expressed in terms of the result of the previous stage and is therefore easy to calculate. Basically, only first order DWBA cross sections are required as input for the calculation of the multi-step cross section, i.e. Eq. (2) serves as the source term. In KAPSIES, up to five steps can be calculated for the FKK model.

Applying residual-system statistics to both the intermediate and final states of the higher order DWBA series gives the two-step cross section of the TUL model [5]:

$$
\begin{aligned}
\frac{d^{2} \sigma^{(2)}\left(E, \Omega \leftarrow E_{0}, \Omega_{0}\right)}{d \Omega d E}= & \sum_{l_{1}, l_{2}} \int \mathrm{d} E_{1}\left(2 l_{2}+1\right) R\left(l_{2}\right) \omega_{1 p 1 h}\left(E_{1}-E\right)\left(2 l_{1}+1\right) R\left(l_{1}\right) \\
& \times \omega_{1 p 1 h}\left(E_{0}-E_{1}\right)\left[\frac{d \sigma^{(2)}\left(E, \Omega \leftarrow E_{1}, \Omega_{1} \leftarrow E_{0}, \Omega_{0}\right)}{d \Omega}\right]_{l_{1}, l_{2}}^{D W B A} .
\end{aligned}
$$

Finally, applying residual-system statistics on the final states only gives the two-step cross section for the NWY model [6], which we estimate by

$$
\begin{aligned}
\frac{d^{2} \sigma^{(2)}\left(E, \Omega \leftarrow E_{0}, \Omega_{0}\right)}{d \Omega d E}= & 16 \sum_{l_{1}, l_{2}}\left(2 l_{2}+1\right) R\left(l_{2}\right) \omega_{2 p 2 h}\left(E_{0}-E\right)\left(2 l_{1}+1\right) R\left(l_{1}\right) \\
& \times\left[\frac{d \sigma^{(2)}\left(E, \Omega \leftarrow E_{1}, \Omega_{1} \leftarrow E_{0}, \Omega_{0}\right)}{d \Omega}\right]_{l_{1}, l_{2}}^{D W B A}
\end{aligned}
$$

In Eqs. (2),(5)-(7), $m$ is the reduced nucleon mass, $l$ is the transferred angular momentum, $l_{1}$ and $l_{2}$ the transferred angular momentum in the first and second step, $E_{0}, \Omega_{0}$ and $E, \Omega$ are the incident and outgoing energy and solid angle, respectively, and $E_{n}, \Omega_{n}$ are the leading-particle energy and solid angle at the $n$th stage. The bar in Eq. (7) denotes an average over intermediate energy, an additional approximation that was needed to bring the original NWY model into a computationally tractable form (see [11]).

In order to compare our results with purely phenomenological approaches, we have also included the systematics of Kalbach [12] in our code system. This parametrization, based on fitting a large number of experimental 


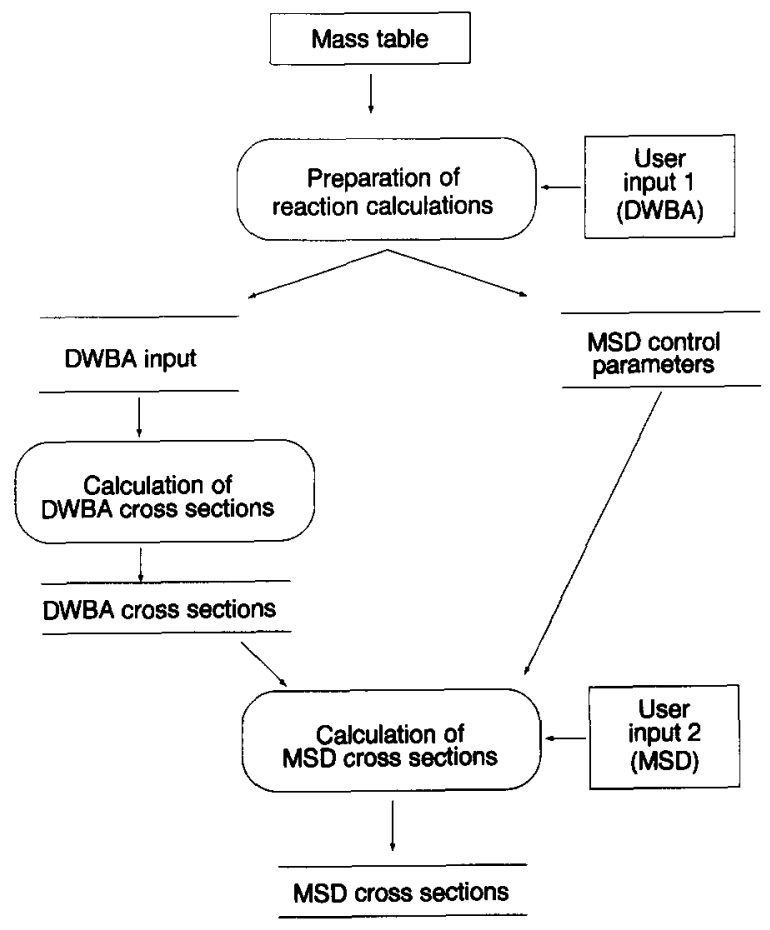

Fig. 2.

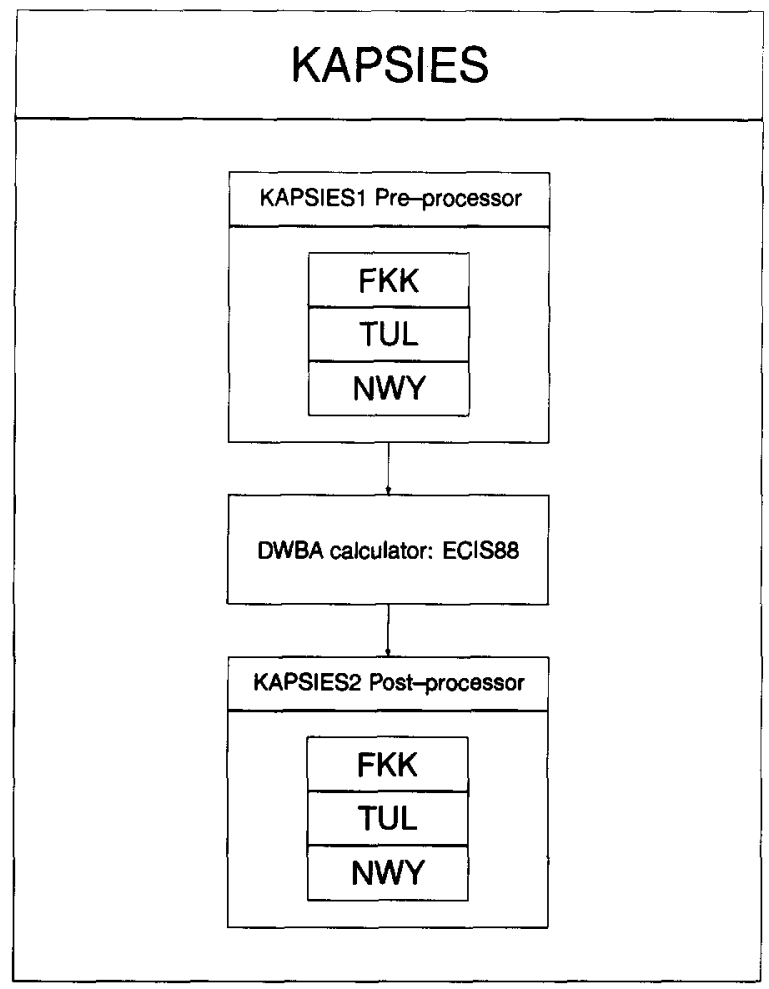

Fig. 3.

Fig. 2. Top-level data-flow diagram for MSD calculations.

Fig. 3. Architecture of code system KAPSIES.

double-differential cross sections, generally provides a good fit to the shape of the pre-equilibrium angular distribution. Kalbach's formula for the double-differential cross section for reactions consisting solely of MSD processes reads

$$
\frac{d^{2} \sigma}{d \Omega d E}=\frac{1}{4 \pi} \frac{d \sigma_{M S D}}{d E} \frac{a}{\sinh (a)} \exp (a \cos \Theta) .
$$

The various constants of this parametrization are given in [12]. For consistency, when we compare our MSD results with Eq. (8), we take the angle-integrated cross section $d \sigma_{M S D} / d E$ as calculated from the MSD models. An attractive feature of the inclusion of Kalbach's systematics is that it provides a very simple check on the MSD model predictions for pre-equilibrium angular distributions.

The left and right continuum cross sections, denoted with a subscript $L$ and $R$, respectively, can be constructed following the previous formulae, on the basis of the corresponding polarized DWBA cross sections. Then, the continuum analyzing power is

$$
A(E, \Theta)=\left(\frac{d^{2} \sigma_{L}(E, \Omega)}{d \Omega d E}-\frac{d^{2} \sigma_{R}(E, \Omega)}{d \Omega d E}\right) /\left(\frac{d^{2} \sigma_{L}(E, \Omega)}{d \Omega d E}+\frac{d^{2} \sigma_{R}(E, \Omega)}{d \Omega d E}\right),
$$

where again the left and right cross sections consist of one- and multi-step terms.

On the basis of the above model equations, it follows that an MSD computer program has to carry out the following functions: 


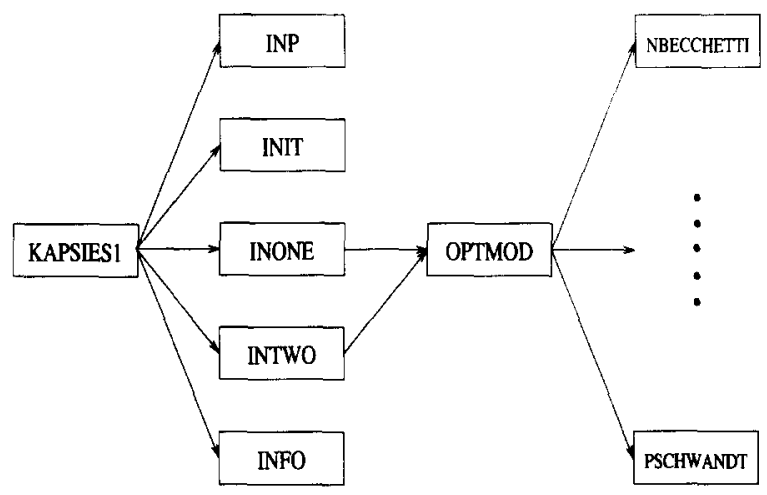

Fig. 4. Structure chart for pre-processor KAPSIESI.

1. Prepare the parameters needed as input for the DWBA computation. They include physical parameters (e.g., reaction type, optical model) and computational parameters (e.g., energy grid) as well as control parameters (e.g., what MSD theory is to be calculated).

2. Calculate the appropriate individual DWBA cross sections.

3. Process these into the desired MSD continuum cross sections. Basically, this consists of integrating the DWBA cross sections over intermediate energies and weighting the results with the appropriate state densities.

This calculation process is pictorially represented in the data-flow diagram of Fig. 2.

\section{Description of the program}

The architecture of KAPSIES is based on the data-flow diagram of Fig. 2. The general structure of the code system is sketched in Fig. 3.

The code system consists of three main parts. The first part is the program KAPSIES1, where the basic parameters for the MSD reaction calculation are specified and a collection of input files for the DWBA calculator is constructed. The middle part consists of a standard DWBA calculator, which is used for the generation of the large number of required DWBA cross sections that underly the MSD cross sections. For this we have opted for the code ECIS88 [18]. The third part is the program KAPSIES2, which processes the DWBA cross sections according to the expressions $(2)-(8)$ in order to obtain the MSD cross sections.

\subsection{Pre-processor KAPSIESI}

In KAPSIES1, the basic information for the MSD reaction is specified and subsequently transformed into input files according to the format of ECIS88. Furthermore, the parameters that are needed for the statistical MSD calculation are written on a file which will be read by the program KAPSIES2. In Fig. 4, a structure chart showing the module structure of KAPSIES1 is given.

In subroutine INP, the input file for KAPSIES1 is read. A sample input file for KAPSIES1 is presented at the end of this paper. For the convenience of the user, we have strived for a self-explanatory input file. The first input variables are the incident energy in the LAB system, the target nucleus and the type of incident particle (proton or neutron). The user can specify the minimal outgoing energy for which the MSD cross section is desired, the number of points on the energy grid (this includes the incident and minimal outgoing energy), NUMMSD, and the maximum transferred angular momentum JMAX. The latter two parameters determine the accuracy (and the amount of computer time) of the calculation. Next, it is specified whether the DWBA cross 
Table 1

The optical models implemented in KAPSIES1 and their associated codes for the user input. The corresponding references can be found in comment lines in the source code.

\begin{tabular}{llll}
\hline Neutrons & Code & Protons & Code \\
\hline Becchetti and Greenlees & nbecc & Becchetti and Greenlees & pbecc \\
Engelbrecht and Fiedeldey & nenge & Madland & pmadl \\
Ferrer et al. & nferr & Menet et al. & pmene \\
Madland & nmadl & Perey and Perey & ppere \\
Moldauer & nmold & Schwandt et al. & pschw \\
Patterson et al. & npatt & & \\
Rapaport et al. & nrapa & & \\
Rosen et al. & nrose & & \\
Smith et al. & nsmit & & \\
Walter and Guss & nwalt & & \\
Wilmore and Hodgson & nwilm & & \\
\hline
\end{tabular}

sections are calculated using relativistic or non-relativistic kinematics, the angle increment ( 5 or 10 degrees) can be given as well as options for the creation of DWBA input files for the FKK model (first order DWBA) and/or for the TUL and NWY models (second order DWBA). These options can be activated by giving a (lowercase) ' $y$ ' in the input. Finally, the optical model parametrizations (for either protons or neutrons) can be chosen together with their range of applicability. Since MSD calculations may extend over a large energy region, complementary prescriptions can be used for different energies. The code for the optical model (see Table 1) and the associated energy range can be given for up to three different ranges.

On the basis of this input, subroutine INIT prepares some basic nuclear reaction quantities such as the mass of the target nucleus (which is read from a mass table) and an equidistant grid of leading-particle and excitation energies.

In subroutine OPTMOD, the optical potentials for the calculation of the initial, intermediate and final distorted waves and for the form factor are generated using optical model systematics. For each point on the energy grid, the optical model parameters are calculated. The predefined optical model algorithms that are included in KAPSIES1 are displayed in Table 1. Further parametrizations can easily be added to the source code by the user.

In subroutine INONE, the first order DWBA input files for ECIS88 are created using the quantities calculated by the aforementioned subroutines. A single ECIS88 input file is characterized by one incident energy and one outgoing energy. For this pair of energies, $(J M A X+1)$ natural parity states (starting with a $0^{+}$-state and increasing up to $J M A X)$ are specified at the corresponding excitation energy. For each residual state, the DWBA cross section will be computed. The form factor is related to the derivative of the optical potential with potential parameters taken at an energy halfway the incident and outgoing energy. The computation of the continuum one-step cross section over the whole energy range requires NUMMSD input files, corresponding with $N U M M S D \times(J M A X+1)$ first order DWBA cross sections. The FKK multi-step cross section basically consists of one-step cross sections, a result of the convolution structure of the model. Besides the outgoing energy, the incident energy of these one-step cross sections is also varied, see Eq. (5). The grid of incident energies (which are, strictly speaking, intermediate energies in the multi-step process) has been taken differently from that of the outgoing energies, in order to allow for a more accurate integration procedure for the multi-step cross sections (which is carried out in the post-processing program KAPSIES2). In addition to the calculation of the continuum one-step cross sections, the multi-step FKK calculation requires a further $N U M M S D \times(N U M M S D-1)$ input files (i.e. $N U M M S D \times(N U M M S D-1) \times(J M A X+1)$ first order DWBA cross sections). For all DWBA calculations, we take a default deformation parameter of 0.02 and perform the strength adjustments in KAPSIES2. 
Analogously, subroutine INTWO generates $N U M M S D^{2} \times(J 1 M A X+1)$ input files, resulting in $N U M M S D^{2}$ $\times(J 1 M A X+1) \times(J 2 M A X+1)$ second order DWBA cross sections that are required for the TUL and NWY model. Here, JIMAX and J2MAX (which are both taken equal to JMAX/2) are the maximum transferred angular momenta in the first and second step, respectively.

Several of the parameters that were specified in the input file or calculated by KAPSIES1 are also needed for the MSD model calculation. In subroutine INFO, these parameters are written to the file KAPSIES1.RES, which will be used directly as an input file for the program KAPSIES2.

\subsection{DWBA calculator ECIS88}

The choice of using the coupled channel code ECIS88 [18] as our DWBA generator was motivated by its general success in predicting direct reaction cross sections for discrete states and its capability of handling a large variety of reaction types over a wide energy range. Of course, a full coupled channels calculation is too detailed for our purposes and would be an unnecessary waste of computer time. However, ECIS88 is perfectly suitable for first and higher order DWBA calculations.

If so desired, KAPSIES 1 may be modified to create input files for other DWBA codes (e.g. DWUCK-4 [19]). Such changes are to be made in subroutines INONE or INTWO of KAPSIES1. For a microscopic MSD description (see e.g. $[8,20]$ ) an additional shell model subroutine will be necessary.

\subsection{Post-processor KAPSIES2}

In the program KAPSIES2, the calculation of the continuum cross sections and analyzing powers is performed. The data produced by KAPSIES1 and ECIS88 are read and processed according to the various MSD prescriptions. A structure chart of KAPSIES2 is given in Fig. 5.

In subroutine INP1 the input from the user is read. A sample user input file for KAPSIES2 is given at the end of this paper. It is divided into four parts.

First, one can specify which MSD model(s) is (are) used for the calculation. Of course, the calculation of the FKK, TUL or NWY cross sections is only possible if the appropriate (first or second order) DWBA cross sections have been produced by ECIS88. Two further options concern the comparison of the calculated continuum angular distributions with the Kalbach systematics and the addition of the third and higher steps of the FKK model to the first two steps of the TUL and NWY model. Up to five steps for the FKK model can be given.

The second part of the input file controls the output of KAPSIES2. One may choose to print the one-step and two-step DWBA cross sections (resulting in a rather voluminous output) and the level density. The output of the MSD cross sections may be presented per outgoing energy (giving angular distributions) and per outgoing angle (giving spectra for each angle). Also, there is an option to print the relative contribution of each step. Finally, the continuum analyzing power for each MSD model can be calculated and printed.

The level density parameters $a, p$ (pairing correction) and $\sigma$ (spin cutoff factor) are read in the third part. The default values (represented by a blank input) can be overruled by alternative values.

In the last part of the input, one can give the parameter CINP which serves to adjust the absolute magnitude of the cross sections. CINP is a multiplication factor for the default value $(0.02)$ of the deformation parameter and should be reasonably close to one.

In subroutine INP2 the file KAPSIES 1.RES is read, which contains the basic parameters (numerical constants, masses, the energy grid, optical potentials, etc.) created by KAPSIES1.

In subroutine INIT, some further numerical constants (such as the kinematical factor of the FKK formula (5) ) required for the MSD calculations are fixed. The strength parameter for the MSD cross section is 


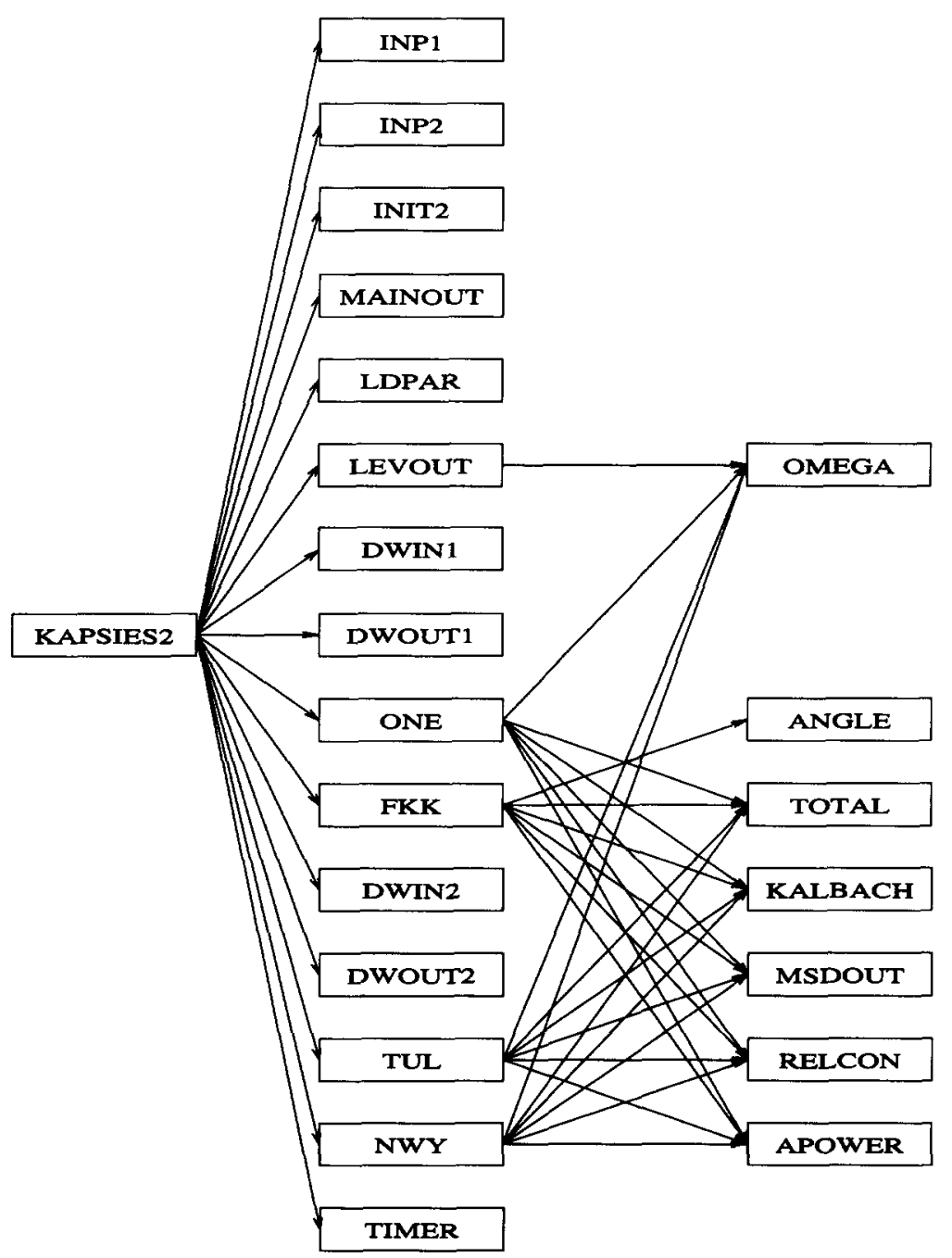

Fig. 5. Structure chart for post-processor KAPSIES2.

$$
C N O R M=C I N P \times \frac{5.0 .10^{6}}{A^{3} E_{\mathrm{inc}}} .
$$

In principle, this is the only adjustable parameter in the calculation. It may be seen as an a posteriori adjustment of the DWBA cross section. The employed deformation parameter is $\beta=\sqrt{C N O R M} \beta_{\text {default }}$ (with $\beta_{\text {default }}=0.02$ ) being used in ECIS88.

Subroutine MAINOUT takes care of the output of the basic information, such as the type of reaction, the incident energy, the print flags and all optical model parameters for each energy.

The level density parameters are computed in subroutine LDPAR. Default parametrizations are built in. For the single-particle state density we take

$$
g=A / 13,
$$

(corresponding to $a \approx A / 8$ ) and the default pairing correction is taken from Dilg et al. [21]. For the spin 
cutoff factor we have [22]

$$
\sigma^{2}=0.24 n A^{2 / 3},
$$

where $n$ is the exciton number. In the input file, these default values can simply be overruled. The spin distribution (4) is also produced in this subroutine.

The particle-hole level density (3) is calculated by the function OMEGA .

The functions $\omega_{p, h}\left(E_{x}\right), R_{2}(J)$ and $\rho\left(E_{x}, J\right)=(2 J+1) R_{2}(J) \omega_{p, h}\left(E_{x}\right)$ are printed in subroutine LEVOUT if the corresponding input value is set to ' $y$ '.

In subroutines DWIN1 and DWIN2, the DWBA one-step and two-step cross sections as calculated by ECIS88 are read from a file called fort.7. Also, the DWBA analyzing power may be read from this file, enabling the computation of the left and right DWBA cross sections. In subroutines DWOUT1 and DWOUT2, the DWBA cross sections are printed.

Subroutine ONE produces the continuum one-step cross sections. Here, the first order DWBA cross sections are multiplied by the state density per angular momentum (see Eq. (2)). The cross sections with the highest incident energy (i.e., the incident energy as given in the input file of KAPSIES1), DSTEP, represent the one-step cross sections for all MSD models. The cross sections with lower incident energies, CSCONT, are employed for the calculation of the FKK multi-step cross section (see Eq. (5)).

Subroutine FKK comprises a recursive calculation of the multi-step cross sections of the FKK model. Basically, it consists of the angle and energy integration of the continuum one-step cross sections. Since the latter are calculated with an incident angle of zero degrees, the double-differential one-step cross sections that represent the second step of the two-step process must be transformed so that the new incident (i.e. intermediate) angle corresponds with the final angle of the first step. This transformation is performed in subroutine ANGLE using the three-dimensional cosine rule. The integration over intermediate energy is done according to Simpson's rule. We note that the accuracy of this integration is important, since errors tend to build up in the higher MSD steps [11].

The double-differential one-step cross sections of subroutine ONE and multi-step cross sections of subroutine FKK are transferred to subroutine TOTAL, where the angle-integrated, energy-integrated and total MSD cross sections (summed over steps) are calculated. The following quantities are produced by TOTAL:

- DSTEP: continuum multi-step direct cross section as a function of step, outgoing energy and angle.

- DSTEPA: continuum multi-step direct cross section as a function of step and outgoing energy (angleintegrated).

- DSTEPE: continuum multi-step direct cross section as a function of step and outgoing angle (energyintegrated).

- DSTEPAE: continuum multi-step direct cross section as a function of step (angle- and energy-integrated).

- DTOT: continuum multi-step direct cross section as a function of outgoing energy and angle (summed over steps).

- DTOTA: continuum multi-step direct cross section as a function of outgoing energy (summed over steps and angle-integrated).

- DTOTE: continuum multi-step direct cross section as a function of outgoing angle (summed over steps and energy-integrated).

- DALL: total continuum multi-step direct cross section.

In subroutine KALBACH the calculated MSD double-differential cross sections are compared with Kalbach's systematics. The angle-integrated cross section (as a function of outgoing energy) DTOTA from the MSD model is used as input for Kalbach's parametrization. For easy comparison, the results are printed next to the columns of the MSD angular distributions.

Subroutine MSDOUT controls the output of the MSD cross sections as delivered by subroutine TOTAL. The options entered in the input file determine whether the cross sections are grouped per angle (double-differential 


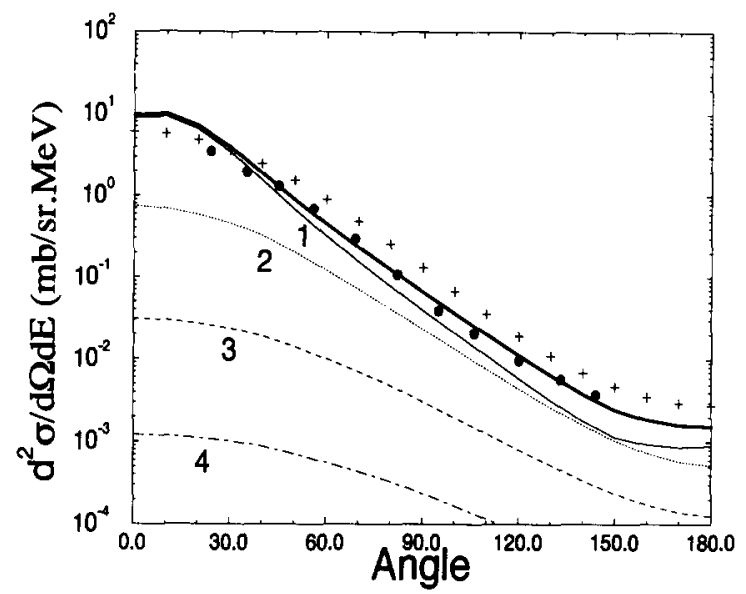

Fig. 6. MSD cross sections according to the FKK model for the $80 \mathrm{MeV}$ (p,p') reaction on ${ }^{90} \mathrm{Zr}$ at an outgoing energy of $60 \mathrm{MeV}$ calculated with KAPSIES. The thick solid line represents the total MSD cross section (summed over steps), the circles the experimental data from Cowley et al. [23] and the pluses the systematics of Kalbach. The corresponding numerical results are given as Test Run Output at the end of this paper.

and energy-integrated), per outgoing energy (double-differential and angle-integrated) or both. The results are presented in columns enabling immediate processing by graphical software.

In subroutine RELCON, the relative contribution of each step is calculated and printed per angle and/or per energy if the corresponding option is set to ' $y$ '. These relative contributions, which may give an alternative insight in the construction of the MSD cross section by the various steps, are obtained by simply dividing the MSD cross section for each separate step by the total result.

In subroutine APOWER, the continuum one-step and multi-step left and right cross sections are collected in order to calculate the continuum analyzing power (see Eq. (9)).

Finally, in subroutine TIMER the execution time is displayed.

The same numerical techniques as employed for the FKK model calculation are also used for the computation of the TUL and NWY two-step cross sections. This task is performed in subroutines TUL and NWY, respectively. Here, the two-step DWBA cross sections are processed according to Eqs. (6) and (7), respectively. These subroutines also call the sequence of subroutines TOTAL, MSDOUT, KALBACH, RELCON and APOWER for a complete cross section and analyzing power calculation.

\section{Implementation and results of KAPSIES}

KAPSIES has been written in standard FORTRAN-77 and currently runs on a DEC-AXP 3000/500 computer and on a SUN SPARC-2 workstation. For both KAPSIES1 and KAPSIES2, a file that contains all common blocks and type declarations has been created and included at the beginning of each subroutine. This reduces the size and improves the readability and maintainability of the source code. The code ECIS88 can be obtained from the NEA Data Bank.

The chosen sample run given at the end of this paper is the ${ }^{90} \mathrm{Zr}+$ p reaction at $80 \mathrm{MeV}$. In part $\mathrm{C}$ of the Test Run Input and Output section, the output corresponding with the input files given in parts A and B is presented. In Fig. 6, a comparison between the results as calculated with the FKK model and the experimental data for one outgoing energy are displayed.

The running time for this sample problem (which consists of a FKK calculation only) on a DEC-AXP $3000 / 500$ computer is $0.55 \mathrm{~s}$ for KAPSIES1, $1.53 \mathrm{~s}$ for KAPSIES2 and $69.54 \mathrm{~s}$ for ECIS88. Clearly, the 
generation of individual DWBA cross sections constitutes the major part (typically $95 \%$ ) of the calculation. The running time for a calculation (with the same energy grid) of the TUL and NWY models is roughly ten times larger because the calculation of second order DWBA cross sections is rather involved. For one specific reaction, the calculations with the codes KAPSIES1 and ECIS88 have to be performed only once. Since the DWBA cross sections are proportional to $\beta_{l}^{2}$ (for small $\beta_{l}$ ), we can perform additional adjustments in the post-processor KAPSIES2 (with the factor CNORM). Hence, the latter code can be used separately from the the other two codes.

The results of the calculations have been placed in a physical perspective in [11] where some comparisons with experimental data were made. There, we came to the conclusion that the FKK model is the most appropriate for routine calculations. Currently, we are extending our code system with the collective, multi-step compound and compound reaction mechanisms, more sophisticated level density prescriptions and more complex reaction types [24]. We hope to publish this code later on. In sum, we believe that the quantum-mechanical approach to pre-equilibrium reactions is now a helpful tool for practical applications.

\section{Acknowledgements}

We wish to thank J. Raynal for many helpful discussions concerning ECIS88 and R.C.L. van der Stad for suggesting us the program acronym.

\section{References}

[1] E. Gadioli and P.E. Hodgson, Pre-equilibrium Nuclear Reactions (Oxford Univ. Press, Oxford, 1992).

[2] R. Bonetti, A.J. Koning, J.M. Akkermans and P.E. Hodgson, Phys. Rep. 247 (1994) I.

[3] A.J. Koning and J.M. Akkermans, Ann. Phys. (NY) 208 (1991) 216.

[4] H. Feshbach, A. Kerman and S. Koonin, Ann. Phys. 125 (1980) 429.

[5] T. Tamura, T. Udagawa and Lenske, Phys. Rev. C 26 (1982) 379.

[6] H. Nishioka, H.A. Weidenmüller and S. Yoshida, Ann. Phys. (NY) 183 (1988) 166

[7] T. Tamura, T. Udagawa and M. Benhamou, Comput. Phys. Commun. 29 (1983) 391

[8] W.A. Richter, A.A. Cowley, R. Lindsay, J.J. Lawrie, S.V. Förtsch, J.V. Pilcher, R. Bonetti and P.E. Hodgson, Phys. Rev. C 46 (1992) 1030.

[9] A.J. Koning, in: Proc. Workshop on Multistep Direct Reactions, Faure (Capetown), South-Africa, ed. R.H. Lemmer (World Scientific, Singapore, 1991) p. 71.

[10] A.J. Koning, in: Proc. Int. Symposium on Nuclear Data Evaluation Methodology, ed. C.L. Dunford (BNL, Brookhaven, 1992) p. 434.

[11] A.J. Koning and J.M. Akkermans, Phys. Rev. C 47 (1993) 724.

[12] C. Kalbach, Phys. Rev. C 37 (1988) 2350.

[13] J.M. Akkermans, H. Gruppelaar and G. Reffo, Phys. Rev. C 22 (1980) 73.

[14] H. Gruppelaar, P. Nagel and P.E. Hodgson, Riv. Nuovo Cimento 9 (1986) 1.

[15] J.M. Akkermans and A.J. Koning, Phys. Lett. B 234 (1990) 417.

[16] E. Běták and J. Dobes, Z. Phys. A 279 (1976) 319.

[17] P. Obložinský, Nucl. Phys. A 453 ( 1986) 127.

[18] J. Raynal, in: Applied Nuclear Theory and Nuclear Model Calculations for Nuclear Technology Applications, eds. M.K. Mehta and J.J. Schmidt (ICTP, Trieste, 1988) p. 506.

[ 19] P.D. Kunz, DWUCK4 code, University of Colorado (technical report)

[20] M.B. Chadwick and P.G. Young, Phys. Rev. C 47 (1993) 2255.

[21] W. Dilg, W. Schantl, H. Vonach and M. Uhl, Nucl. Phys. A 217 (1973) 269.

[22] H. Gruppelaar, in: Proc. IAEA Advisory Group Meeting on Basic and Applied Problems on Nuclear Level Densities (BNL, Brookhaven, 1983) p. 143.

$123]$ A.A. Cowley, A. van Kent, J.J. Lawrie, S.V. Förtsch, D.M. Whittal, J.V. Pilcher, F.D. Smit, W.A. Richter, R. Lindsay, I.J. van Heerden, R. Bonetti and P.E. Hodgson, Phys. Rev. C 43 (1991) 678.

[24] A.J. Koning, O. Bersillon and J.-P. Delaroche, in: Proc. Meeting on Intermediate Energy Nuclear Data, NEA Data Bank, Issy-lesMoulineaux, France, 30 May - 1 June 1994, to be published. 


\section{TEST RUN INPUT AND OUTPUT}

\section{A. Sample input file for KAPSIES1}

\begin{tabular}{|c|c|c|}
\hline & GENERAL & \\
\hline 80.0 & $=$ Incident energy in $\mathrm{MeV}$ & $:(f 6.2)$ \\
\hline 90ZR & $=$ Target (Uppercase) & $:(i 3, a 2)$ \\
\hline $\mathrm{p}$ & $=$ Projectile (n or p) & : (a1) \\
\hline 20.0 & $=$ Minimal Outgoing Energy (blank=E-inc/5) : & $:(f 6.2)$ \\
\hline 7 & $=$ Number of Energy Points $(\max =13, \mathrm{blank}=6)$ & : (i3) \\
\hline & $=$ Maximal Residual spin $\quad(\max =8, \mathrm{blank}=6)$ & : (i3) \\
\hline $\mathrm{y}$ & $=$ Relativistic kinematics $(y / n)$ & : (a1) \\
\hline y & $=$ Angle increment $10 \mathrm{deg} .(y / n, n=5 \mathrm{deg})$. & : (a1) \\
\hline y & $=$ FKK calculation $(y / n)$ : & : (a1) \\
\hline $\mathrm{n}$ & $=$ TUL + NWY calculation $(y / n)$ & : (a1) \\
\hline & CAL POTENTIALS $(a 5, f 5.1,1 x, f 5.1)$ & \\
\hline pbecc $0.0-50.0$ & $=$ Optical model code, begin and end point & \\
\hline pmadl 50.0-100.0 & $\begin{array}{l}=\text { Optical model code, begin and end point } \\
=\text { Optical model code, begin and end point }\end{array}$ & \\
\hline
\end{tabular}

\section{B. Sample input file for KAPSIES2}

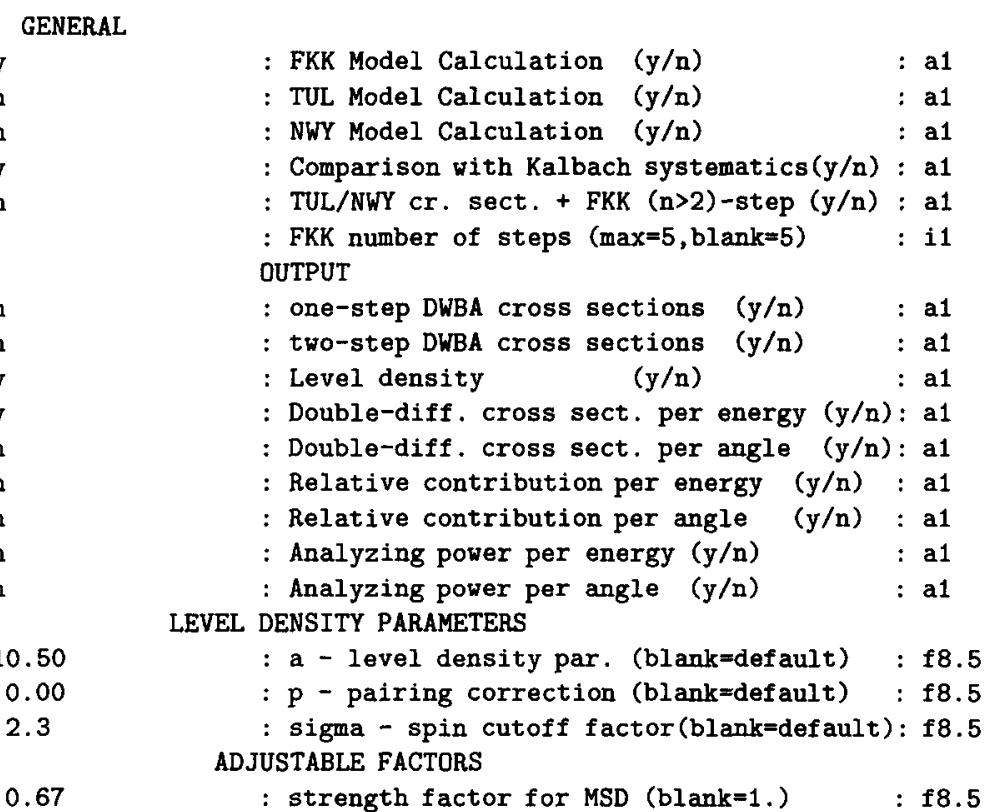




\title{
C. Sample output for KAPSIES
}

KAPSIES

\author{
Version: 1.0 \\ Date : July 20, 1994 \\ Author: Arjan Koning
}

Netherlands Energy Research Foundation ECN

P.0. Box 1, NL-1755 ZG Petten, The Netherlands

FAX: $(+31) 22463490$

Telephone: (+31) 22464078

Email-address: koningtecn.nl

$\begin{aligned} \text { Description References: } & \text { - A.J. Koning, Multi-step direct reactions, PhD thesis (1992) } \\ & - \text { A.J. Koning and J.M. Akkermans, Phys. Rev. C47, 724 (1993) } \\ & - \text { A.J. Koning and J.M. Akkermans, Comput. Phys, Commun. (1994) }\end{aligned}$

This program calculates statistical multi-step direct cross sections and analyzing powers according to the

- Feshbach-Keraan-Koonin (FKK) model

- Tamura-Udagawa-Lenske (TUL) model

- Nishioka-Weidenmuller-Yoshida (NWY) model

All energies are expressed in MeV

All angles are expressed in degrees

All cross sections are expressed in mb

Target : 90zR

Incident particle : $\mathrm{P}$

Incident energy (LAB) : $80.00 \mathrm{MeV}$

OuTPuT

- Optical potential

- Level density

- FKK model

- Double-differential cross section per energy

- Comparison with Kalbach systematics

Optical potential parameters for proton

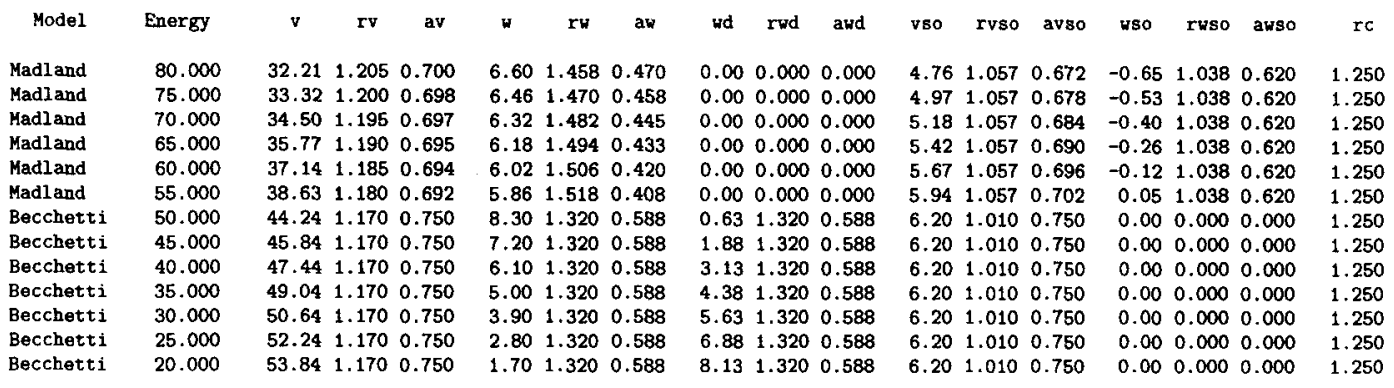

Unbound state density with level density parameter $a=10.500 / \mathrm{MeV}(\mathrm{g}=6,383 / \mathrm{MeV}$ ) and pairing correction $\mathrm{p}=0.00 \mathrm{MeV}$

Energy $\quad U$ 1p $1 \mathrm{~h}$

$4.940 \quad 4.940 \quad 0.20128 \mathrm{E}+03$

$9.890 \quad 9.890 \quad 0.40297 \mathrm{E}+03$

$14.830 \quad 14.830 \quad 0.60426 \mathrm{E}+03$

$19.780 \quad 19.780 \quad 0.80595 E+03$

$\begin{array}{lll}24.720 & 24.720 & 0.10072 \mathrm{E}+04\end{array}$

$29.670 \quad 29.670 \quad 0.12089 \mathrm{E}+04$

$34.610 \quad 34.610 \quad 0.14102 \mathrm{E}+04$

$39.560 \quad 39.560 \quad 0.15483 \mathrm{E}+04$ 


$\begin{array}{lll}44.500 & 44.500 & 0.15483 \mathrm{E}+04 \\ 49.450 & 49.450 & 0.15483 \mathrm{E}+04 \\ \mathbf{5 4 . 3 9 0} & \mathbf{5 4 . 3 9 0} & 0.15483 \mathrm{E}+04 \\ \mathbf{5 9 . 3 3 0} & 59.330 & 0.15483 \mathrm{E}+04\end{array}$

Spin distribution with spin cut-off factor $=2.300$

$\begin{array}{ll}J & R 2(J) \\ & \\ 0 & 0.01601 \\ 1 & 0.03976 \\ 2 & 0.04541 \\ 3 & 0.03605 \\ 4 & 0.02176 \\ 5 & 0.01034 \\ 6 & 0.00393\end{array}$

Sum (over J) of $(2 J+1) * R 2(J)=0.975$

Angular momentum dependent 1p1h unbound state density

$\begin{array}{rcccccccc}\text { Energy } & \mathrm{U} & \mathrm{J}=0 & \mathrm{~J}=1 & \mathrm{~J}=2 & \mathrm{~J}=3 & \mathrm{~J}=4 & \mathrm{~J}=5 & \mathrm{~J}=6 \\ & & & & & & & & \\ 4.940 & 4.940 & 0.32229 \mathrm{E}+01 & 0.24010 \mathrm{E}+02 & 0.45697 \mathrm{E}+02 & 0.50799 \mathrm{E}+02 & 0.39424 \mathrm{E}+02 & 0.22886 \mathrm{E}+02 & 0.10282 \mathrm{E}+02 \\ 9.890 & 9.890 & 0.64523 \mathrm{E}+01 & 0.48068 \mathrm{E}+02 & 0.91487 \mathrm{E}+02 & 0.10170 \mathrm{E}+03 & 0.78927 \mathrm{E}+02 & 0.45818 \mathrm{E}+02 & 0.20585 \mathrm{E}+02 \\ 14.830 & 14.830 & 0.96751 \mathrm{E}+01 & 0.72078 \mathrm{E}+02 & 0.13718 \mathrm{E}+03 & 0.15250 \mathrm{E}+03 & 0.11835 \mathrm{E}+03 & 0.68704 \mathrm{E}+02 & 0.30867 \mathrm{E}+02 \\ 19.780 & 19.780 & 0.12905 \mathrm{E}+02 & 0.96136 \mathrm{E}+02 & 0.18297 \mathrm{E}+03 & 0.20340 \mathrm{E}+03 & 0.15785 \mathrm{E}+03 & 0.91637 \mathrm{E}+02 & 0.4117 \pm \mathrm{E}+02 \\ 24.720 & 24.720 & 0.16127 \mathrm{E}+02 & 0.12015 \mathrm{E}+03 & 0.22867 \mathrm{E}+03 & 0.25420 \mathrm{E}+03 & 0.19728 \mathrm{E}+03 & 0.11452 \mathrm{E}+03 & 0.51453 \mathrm{E}+02 \\ 29.670 & 29.670 & 0.19357 \mathrm{E}+02 & 0.14420 \mathrm{E}+03 & 0.27446 \mathrm{E}+03 & 0.30510 \mathrm{E}+03 & 0.23678 \mathrm{E}+03 & 0.13745 \mathrm{E}+03 & 0.61756 \mathrm{E}+02 \\ 34.610 & 34.610 & 0.22580 \mathrm{E}+02 & 0.16821 \mathrm{E}+03 & 0.32016 \mathrm{E}+03 & 0.35690 \mathrm{E}+03 & 0.27620 \mathrm{E}+03 & 0.16034 \mathrm{E}+03 & 0.72038 \mathrm{E}+02 \\ 39.560 & 39.560 & 0.24791 \mathrm{E}+02 & \mathbf{0 . 1 8 4 6 9 \mathrm { E } + 0 3} & 0.35152 \mathrm{E}+03 & 0.39076 \mathrm{E}+03 & 0.30326 \mathrm{E}+03 & 0.17605 \mathrm{E}+03 & 0.79094 \mathrm{E}+02 \\ 44.500 & 44.500 & 0.24791 \mathrm{E}+02 & 0.18469 \mathrm{E}+03 & 0.35152 \mathrm{E}+03 & 0.39076 \mathrm{E}+03 & 0.30326 \mathrm{E}+03 & 0.17605 \mathrm{E}+03 & 0.79094 \mathrm{E}+02 \\ 49.450 & 49.450 & 0.24791 \mathrm{E}+02 & 0.18469 \mathrm{E}+03 & 0.35152 \mathrm{E}+03 & 0.39076 \mathrm{E}+03 & 0.30326 \mathrm{E}+03 & 0.17605 \mathrm{E}+03 & 0.79094 \mathrm{E}+02 \\ 54.390 & 54.390 & 0.24791 \mathrm{E}+02 & 0.18469 \mathrm{E}+03 & 0.35152 \mathrm{E}+03 & 0.39076 \mathrm{E}+03 & 0.30326 \mathrm{E}+03 & 0.17605 \mathrm{E}+03 & 0.79094 \mathrm{E}+02 \\ 59.330 & 59.330 & 0.24791 \mathrm{E}+02 & 0.18469 \mathrm{E}+03 & 0.35152 \mathrm{E}+03 & 0.39076 \mathrm{E}+03 & 0.30326 \mathrm{E}+03 & 0.17605 \mathrm{E}+03 & 0.79094 \mathrm{E}+02\end{array}$

FKK Model

\begin{abstract}
Beta (ECIS88) : -0.02000 Normalization factors: cinp= 0.67000 (cnorm= 0.05744 ) New Beta: -0.00479
\end{abstract}
Continuum cross section for E-out= $70.00 \mathrm{MeV}$

\begin{tabular}{|c|c|c|c|c|c|c|c|}
\hline Angle & 1-step & $2-s t e p$ & 3-step & 4-step & 5-step & Total & Kalbach \\
\hline 0.0 & $0.50905 \mathrm{E}+01$ & $0.11525 \mathrm{E}+00$ & $0.27582 \mathrm{E}-02$ & $0.77860 \mathrm{E}-04$ & $0.23880 E-05$ & $0.52085 E+01$ & $0.39327 \mathrm{E}+01$ \\
\hline 10.0 & $0.57697 E+01$ & $0.10519 E+00$ & $0.26298 \mathrm{E}-02$ & $0.75591 \mathrm{E}-04$ & $0.23410 \mathrm{E}-05$ & $0.58776 \mathrm{E}+01$ & $0.36440 E+01$ \\
\hline 20.0 & $0.39316 \mathrm{E}+01$ & $0.87240 \mathrm{E}-01$ & $0.23579 \mathrm{E}-02$ & $0.70239 \mathrm{E}-04$ & $0.22195 \mathrm{E}-05$ & $0.40212 \mathrm{E}+01$ & $0.29059 \mathrm{E}+01$ \\
\hline 30.0 & $0.18959 \mathrm{E}+01$ & $0.66664 \mathrm{E}-01$ & $0.20292 \mathrm{E}-02$ & $0.63835 E-04$ & $0.20807 E-05$ & $0.19647 E+01$ & $0.20080 \mathrm{E}+01$ \\
\hline 40.0 & $0.74552 E+00$ & $0.45326 \mathrm{E}-01$ & $0.16959 \mathrm{E}-02$ & $0.53793 \mathrm{E}-04$ & $0.18258 E-05$ & $0.79249 \mathrm{E}+00$ & $0.12159 E+01$ \\
\hline 50.0 & $0.30451 \mathrm{E}+00$ & $0.26743 \mathrm{E}-01$ & $0.11513 E-02$ & $0.42788 E-04$ & $0.15392 \mathrm{E}-05$ & $0.33245 \mathrm{E}+00$ & $0.65516 \mathrm{E}+00$ \\
\hline 60.0 & $0.13329 \mathrm{E}+\infty 0$ & $0.14729 \mathrm{E}-01$ & $0.77571 \mathrm{E}-03$ & $0.32209 \mathrm{E}-04$ & $0.12390 \mathrm{E}-05$ & $0.14882 E+00$ & $0.32005 \mathrm{E}+00$ \\
\hline 70.0 & $0.58916 \mathrm{E}-01$ & $0.81799 E-02$ & $0.51991 E-03$ & $0.24138 \mathrm{E}-04$ & $0.99650 \mathrm{E}-06$ & $0.67641 \mathrm{E}-01$ & $0.14488 \mathrm{E}+00$ \\
\hline 80.0 & $0.27774 E-01$ & $0.45136 \mathrm{E}-02$ & $0.34100 \mathrm{E}-03$ & $0.17870 \mathrm{E}-04$ & $0.79836 \mathrm{E}-06$ & $0.32647 \mathrm{E}-01$ & $0.62248 E-01$ \\
\hline 90.0 & $0.12639 \mathrm{E}-01$ & $0.23606 \mathrm{E}-02$ & $0.20382 E-03$ & $0.12051 \mathrm{E}-04$ & $0.58722 E-06$ & $0.15216 \mathrm{E}-01$ & $0.26047 E-01$ \\
\hline 100.0 & $0.60910 \mathrm{E}-02$ & $0.12706 \mathrm{E}-02$ & $0.12388 \mathrm{E}-03$ & $0.81498 \mathrm{E}-05$ & $0.43117 \mathrm{E}-06$ & $0.74940 \mathrm{E}-02$ & $0.10899 E-01$ \\
\hline 110.0 & $0.27811 E-02$ & $0.67793 \mathrm{E}-03$ & $0.73588 \mathrm{E}-04$ & $0.53202 E-05$ & $0.30389 \mathrm{E}-06$ & $0.35382 E-02$ & $0.46830 \mathrm{E}-02$ \\
\hline 120.0 & $0.13680 \mathrm{E}-02$ & $0.36430 \mathrm{E}-03$ & $0.43972 \mathrm{E}-04$ & $0.34985 \mathrm{E}-05$ & $0.21632 E-06$ & $0.17800 \mathrm{E}-02$ & $0.21198 \mathrm{E}-02$ \\
\hline 130.0 & $0.65971 \mathrm{E}-03$ & $0.20237 \mathrm{E}-03$ & $0.26966 \mathrm{E}-04$ & $0.23426 \mathrm{E}-05$ & $0.15623 E-06$ & $0.89155 \mathrm{E}-03$ & $0.10356 \mathrm{E}-02$ \\
\hline 140.0 & $0.37108 \mathrm{E}-03$ & $0.11342 E-03$ & $0.16254 \mathrm{E}-04$ & $0.15262 \mathrm{E}-05$ & $0.10953 \mathrm{E}-06$ & $0.50239 E-03$ & $0.55797 \mathrm{E}-03$ \\
\hline 150.0 & $0.23501 \mathrm{E}-03$ & $0.68607 \mathrm{E}-04$ & $0.10517 \mathrm{E}-04$ & $0.10666 \mathrm{E}-05$ & $0.82024 \mathrm{E}-07$ & $0.31528 E-03$ & $0.33788 \mathrm{E}-03$ \\
\hline 160.0 & $0.17781 E-03$ & $0.44972 \mathrm{E}-04$ & $0.71412 \mathrm{E}-05$ & $0.76771 \mathrm{E}-06$ & $0.62482 E-07$ & $0.23075 E-03$ & $0.23348 \mathrm{E}-03$ \\
\hline 170.0 & $0.15380 \mathrm{E}-03$ & $0.33861 E-04$ & $0.54648 \mathrm{E}-0.5$ & $0.61384 E-06$ & $0.52161 \mathrm{E}-07$ & $0.19379 \mathrm{E}-03$ & $0.18618 \mathrm{E}-03$ \\
\hline 180.0 & $0.13833 E-03$ & $0.29795 \mathrm{E}-04$ & $0.48193 E-05$ & $0.55235 \mathrm{E}-06$ & $0.47870 \mathrm{E}-07$ & $0.17355 \mathrm{E}-03$ & $0.17252 \mathrm{E}-03$ \\
\hline $\begin{array}{l}\text { Angle } \\
\text { integr. }\end{array}$ & $0.47395 \mathrm{E}+01$ & $0.17821 E+\infty 0$ & $0.67962 \mathrm{E}-02$ & $0.26053 E-03$ & $0.10020 \mathrm{E}-04$ & $0.49248 \mathrm{E}+01$ & \\
\hline \multicolumn{8}{|c|}{ Continuum cross } \\
\hline Angle & 1 -step & 2-step & $3-s t e p$ & 4-step & 5-step & Total & Kalbach \\
\hline 0.0 & $0.88194 E+01$ & $0.74826 \mathrm{E}+00$ & $0.30781 \mathrm{E}-01$ & $0.12128 \mathrm{E}-02$ & $0.47206 \mathrm{E}-04$ & $0.95997 \mathrm{E}+01$ & $0.60644 \mathrm{E}+01$ \\
\hline 10.0 & $0.92255 \mathrm{E}+01$ & $0.69213 E+\infty$ & $0.29572 \mathrm{E}-01$ & $0.11833 \mathrm{E}-02$ & $0.46440 \mathrm{E}-04$ & $0.99484 \mathrm{E}+01$ & $0.57204 \mathrm{E}+01$ \\
\hline 20.0 & $0.65078 E+01$ & $0.58447 \mathrm{E}+00$ & $0.26801 \mathrm{E}-01$ & $0.11075 E-02$ & $0.44262 E-04$ & $0.71203 E+01$ & $0.48095 \mathrm{E}+01$ \\
\hline 30.0 & $0.34334 E+01$ & $0.45708 \mathrm{E}+00$ & $0.23369 \mathrm{E}-01$ & $0.10149 \mathrm{E}-02$ & $0.41723 E-04$ & $0.39149 \mathrm{E}+01$ & $0.36234 E+01$ \\
\hline
\end{tabular}




$\begin{array}{rlll}40.0 & 0.15229 \mathrm{E}+01 & 0.32309 \mathrm{E}+00 & 0.18847 \mathrm{E}-01 \\ 50.0 & 0.68268 \mathrm{E}+00 & 0.20183 \mathrm{E}+00 & 0.14096 \mathrm{E}-01 \\ 60.0 & 0.31761 \mathrm{E}+00 & 0.11926 \mathrm{E}+00 & 0.99993 \mathrm{E}-02 \\ 70.0 & 0.15181 \mathrm{E}+00 & 0.70172 \mathrm{E}-01 & 0.69937 \mathrm{E}-02 \\ 80.0 & 0.77030 \mathrm{E}-01 & 0.40932 \mathrm{E}-01 & 0.48054 \mathrm{E}-02 \\ 90.0 & 0.39229 \mathrm{E}-01 & 0.22962 \mathrm{E}-01 & 0.30624 \mathrm{E}-02 \\ 100.0 & 0.20700 \mathrm{E}-01 & 0.13198 \mathrm{E}-01 & 0.19729 \mathrm{E}-02 \\ 110.0 & 0.10948 \mathrm{E}-01 & 0.75535 \mathrm{E}-02 & 0.12481 \mathrm{E}-02 \\ 120.0 & 0.58191 \mathrm{E}-02 & 0.43768 \mathrm{E}-02 & 0.79549 \mathrm{E}-03 \\ 130.0 & 0.32012 \mathrm{E}-02 & 0.26188 \mathrm{E}-02 & 0.52018 \mathrm{E}-03 \\ 140.0 & 0.17974 \mathrm{E}-02 & 0.15947 \mathrm{E}-02 & 0.33820 \mathrm{E}-03 \\ 150.0 & 0.11430 \mathrm{E}-02 & 0.10390 \mathrm{E}-02 & 0.23435 \mathrm{E}-03 \\ 160.0 & 0.93037 \mathrm{E}-03 & 0.72767 \mathrm{E}-03 & 0.17044 \mathrm{E}-03 \\ 170.0 & 0.86093 \mathrm{E}-03 & 0.57480 \mathrm{E}-03 & 0.13749 \mathrm{E}-03 \\ 180.0 & 0.89495 \mathrm{E}-03 & 0.51658 \mathrm{E}-03 & 0.12446 \mathrm{E}-03 \\ & & & \\ \text { Angle } & 0.85218 \mathrm{E}+01 & 0.12963 \mathrm{E}+01 & 0.84448 \mathrm{E}-01 \\ \text { integr } & & & \end{array}$

Continuum cross section for E-out $=50.00 \mathrm{MeV}$.

$\begin{array}{rccc}\text { Angle } & 1 \text {-step } & 2 \text {-step } & 3 \text {-step } \\ & & & \\ 0.0 & 0.86524 \mathrm{E}+01 & 0.17253 \mathrm{E}+01 & 0.13301 \mathrm{E}+00 \\ 10.0 & 0.87853 \mathrm{E}+01 & 0.16195 \mathrm{E}+01 & 0.12868 \mathrm{E}+00 \\ 20.0 & 0.65680 \mathrm{E}+01 & 0.14066 \mathrm{E}+01 & 0.11852 \mathrm{E}+00 \\ 30.0 & 0.39409 \mathrm{E}+01 & 0.11451 \mathrm{E}+01 & 0.10552 \mathrm{E}+00 \\ 40.0 & 0.21213 \mathrm{E}+01 & 0.86219 \mathrm{E}+00 & 0.88413 \mathrm{E}-01 \\ 50.0 & 0.11318 \mathrm{E}+01 & 0.58955 \mathrm{E}+00 & 0.69754 \mathrm{E}-01 \\ 60.0 & 0.60347 \mathrm{E}+00 & 0.38793 \mathrm{E}+00 & 0.53034 \mathrm{E}-01 \\ 70.0 & 0.32359 \mathrm{E}+00 & 0.25253 \mathrm{E}+00 & 0.39618 \mathrm{E}-01 \\ 80.0 & 0.18142 \mathrm{E}+00 & 0.16213 \mathrm{E}+00 & 0.29133 \mathrm{E}-01 \\ 90.0 & 0.10480 \mathrm{E}+00 & 0.10195 \mathrm{E}+00 & 0.20435 \mathrm{E}-01 \\ 100.0 & 0.62150 \mathrm{E}-01 & 0.65032 \mathrm{E}-01 & 0.14369 \mathrm{E}-01 \\ 110.0 & 0.37776 \mathrm{E}-01 & 0.41432 \mathrm{E}-01 & 0.99799 \mathrm{E}-02 \\ 120.0 & 0.23675 \mathrm{E}-01 & 0.26887 \mathrm{E}-01 & 0.69994 \mathrm{E}-02 \\ 130.0 & 0.15023 \mathrm{E}-01 & 0.18082 \mathrm{E}-01 & 0.50355 \mathrm{E}-02 \\ 140.0 & 0.10244 \mathrm{E}-01 & 0.12532 \mathrm{E}-01 & 0.36547 \mathrm{E}-02 \\ 150.0 & 0.74500 \mathrm{E}-02 & 0.93001 \mathrm{E}-02 & 0.28000 \mathrm{E}-02 \\ 160.0 & 0.66442 \mathrm{E}-02 & 0.73841 \mathrm{E}-02 & 0.22472 \mathrm{E}-02 \\ 170.0 & 0.77157 \mathrm{E}-02 & 0.63737 \mathrm{E}-02 & 0.19457 \mathrm{E}-02 \\ 180.0 & 0.97390 \mathrm{E}-02 & 0.59458 \mathrm{E}-02 & 0.18222 \mathrm{E}-02 \\ & & & \\ \text { Angle } & 0.10272 \mathrm{E}+02 & 0.36812 \mathrm{E}+01 & 0.43695 \mathrm{E}+00 \\ \text { integr. } & & & \end{array}$

4-step

5-step

Total

$0.75975 E-02$ $0.74407 \mathrm{E}-02$ $0.70406 \mathrm{E}-02$ $0.65361 \mathrm{E}-02$ $0.57719 \mathrm{E}-02$ $0.49015 \mathrm{E}-02$

$0.40375 E=02$

$0.32735 \mathrm{E}-02$

$0.26347 \mathrm{E}-02$

$0.20205 E-02$

$0.15431 E=02$

$0.11561 \mathrm{E}-02$

$0.87554 \mathrm{E}-03$

$0.67430 \mathrm{E}-03$

$0.51781 \mathrm{E}-03$

$0.41803 \mathrm{E}-03$

$0.34743 E-03$

$0.30840 \mathrm{E}-03$

$0.29247 \mathrm{E}-03$

0.33259E-01
$0.37178 \mathrm{E}-04$

$0.32023 \mathrm{E}-04$

$0.26613 \mathrm{E}-04$

$0.21916 \mathrm{E}-04$

$0.18041 E-04$

$0.13850 \mathrm{E}-04$

$0.10609 \mathrm{E}-04$

$0.78601 E-05$

$0.58955 \mathrm{E}-05$

$0.44810 \mathrm{E}-05$

$0.33375 E-05$

$0.26353 \mathrm{E}-05$

$0.21169 \mathrm{E}-0.5$

$0.18385 \mathrm{E}-05$

$0.17218 \mathrm{E}-05$

$0.21858 \mathrm{E}-03$
$0.18657 \mathrm{E}+01$

$0.89935 \mathrm{E}+00$

$0.44745 \mathrm{E}+00$

$0.22943 \mathrm{E}+00$

$0.12312 \mathrm{E}+00$

$0.65502 \mathrm{E}-01$

$0.36048 \mathrm{E}-01$

0. 19873E-01

$0.11078 \mathrm{E}-01$

$0.64018 \mathrm{E}-02$

$0.37735 \mathrm{E}-02$

$0.24486 \mathrm{E}-02$

$0.18532 \mathrm{E}-02$

$0.15940 \mathrm{E}-02$

$0.15552 \mathrm{E}-02$

$0.99073 E+01$
$0.38264 \mathrm{E}-03$ $0.37719 \mathrm{E}-03$

$0.36242 \mathrm{E}-03$

$0.34461 \mathrm{E}-03$

$0.31389 \mathrm{E}-03$

$0.27854 \mathrm{E}-03$

$0.24085 \mathrm{E}-03$

$0.20569 \mathrm{E}-03$

$0.17554 \mathrm{E}-03$

$0.14330 \mathrm{E}-03$

$0.11635 \mathrm{E}-03$

$0.92425 \mathrm{E}-04$

$0.74407 \mathrm{E}-04$

$0.60674 \mathrm{E}-04$

$0.49103 \mathrm{E}-04$

$0.41583 \mathrm{E}-04$

$0.35805 \mathrm{E}-04$

$0.32598 \mathrm{E}-04$

$0.31274 \mathrm{E}-04$

$0.20654 \mathrm{E}-02$
$0.10519 \mathrm{E}+02$ $0.10541 \mathrm{E}+02$

$0.81006 \mathrm{E}+01$

$0.51985 \mathrm{E}+01$

$0.30780 \mathrm{E}+01$

$0.17963 \mathrm{E}+01$

$0.10487 \mathrm{E}+01$

$0.61922 \mathrm{E}+00$

$0.37549 \mathrm{E}+00$

$0.22935 \mathrm{E}+00$

$0.14321 E+00$

$0.90436 \mathrm{E}-01$

$0.58511 \mathrm{E}-01$

$0.38876 \mathrm{E}-01$

$0.26997 \mathrm{E}-01$

$0.20010 \mathrm{E}-01$

$0.16659 \mathrm{E}-01$

$0.16376 \mathrm{E}-01$

o. 17831E-01

$0.14425 \mathrm{E}+02$
$0.24671 \mathrm{E}+01$

$0.15361 \mathrm{E}+01$

$0.88719 \mathrm{E}+\infty$

$0.48335 E+00$

$0.25302 E+00$

$0.12979 \mathrm{E}+00$

$0.66578 \mathrm{E}-0$.

$0.34852 \mathrm{E}-01$

$0.18988 \mathrm{E}-01$

$0.10967 \mathrm{E}-01$

$0.68281 \mathrm{E}-02$

$0.46492 \mathrm{E}-02$

$0.35026 \mathrm{E}-02$

$0.29449 \mathrm{E}-02$

$0.27778 \mathrm{E}-02$
Kalbach

$0.67312 E+01$

$0.64388 \mathrm{E}+01$

$0.56432 E+01$

$0.45498 \mathrm{E}+01$

$0.33966 \mathrm{E}+01$

$0.23689 \mathrm{E}+01$

$0.15605 \mathrm{E}+01$

$0.98330 \mathrm{E}+00$

$0.60105 E+00$

$0.36177 \mathrm{E}+00$

$0.21775 E+00$

$0.13310 \mathrm{E}+00$

$0.83870 \mathrm{E}-01$

$0.55248 \mathrm{E}-01$

$0.38532 E-01$

$0.28766 \mathrm{E}-01$

$0.23193 E-01$

$0.20327 \mathrm{E}-01$

$0.19444 \mathrm{E}-01$

Continuum cross section for E-out $=40.00 \mathrm{MeV}$

$\begin{array}{rc}\text { Angle } & 1-\mathrm{step} \\ & \\ 0.0 & 0.50355 \mathrm{E}+01 \\ 10.0 & 0.49774 \mathrm{E}+01 \\ 20.0 & 0.39838 \mathrm{E}+01 \\ 30.0 & 0.27524 \mathrm{E}+01 \\ 40.0 & 0.17530 \mathrm{E}+01 \\ 50.0 & 0.10398 \mathrm{E}+01 \\ 60.0 & 0.60559 \mathrm{E}+00 \\ 70.0 & 0.33883 \mathrm{E}+00 \\ 80.0 & 0.20203 \mathrm{E}+00 \\ 90.0 & 0.12207 \mathrm{E}+00 \\ 100.0 & 0.78500 \mathrm{E}-01 \\ 110.0 & 0.51063 \mathrm{E}-01 \\ 120.0 & 0.34471 \mathrm{E}-01 \\ 130.0 & 0.24786 \mathrm{E}-01 \\ 140.0 & 0.17693 \mathrm{E}-01 \\ 150.0 & 0.14487 \mathrm{E}-01 \\ 160.0 & 0.13188 \mathrm{E}-01 \\ 170.0 & 0.15030 \mathrm{E}-01 \\ 180.0 & 0.17765 \mathrm{E}-01\end{array}$

2 -step
$0.19912 E+01$
$0.19012 E+01$
$0.17064 E+01$
$0.14529 E+01$
$0.11670 E+01$
$0.87071 E+00$
$0.62886 E+00$
$0.44469 E+00$
$0.30722 E+00$
$0.20954 E+00$
$0.14329 E+00$
$0.97772 E-01$
$0.68038 E-01$
$0.49054 E-01$
$0.36658 E-01$
$0.29222 E-01$
$0.24737 E-01$
$0.22314 E-01$
$0.21303 E-01$

3-step

4-step

5-step

Total

Kalbach

.21024E-01

$0.13490 \mathrm{E}-02$

$0.13324 \mathrm{E}-02$

$0.25123 \mathrm{E}+00$

$0.23559 \mathrm{E}+\infty 0$

$0.21463 E+00$

$0.18687 \mathrm{E}+00$

$0.15550 \mathrm{E}+00$

$0.12602 E+\infty 0$

$0.99955 \mathrm{E}-01$

$0.77890 \mathrm{E}-01$

$0.59106 \mathrm{E}-01$

$0.44501 \mathrm{E}-01$

$0.33156 \mathrm{E}-01$

$0.24918 \mathrm{E}-01$

$0.19131 \mathrm{E}-01$

$0.14888 \mathrm{E}-01$

$0.12123 \mathrm{E}-01$

$0.10278 \mathrm{E}-01$

$0.92341 \mathrm{E}-02$

$0.19785 \mathrm{E}-01$

0.129098

$0.12382 \mathrm{E}-02$

$0.18619 \mathrm{E}-01$

$0.16879 E-01$

$0.14869 \mathrm{E}-01$

$0.12818 \mathrm{E}-01$

$0.11501 \mathrm{E}-02$

$0.10487 \mathrm{E}-02$

$0.93875 \mathrm{E}-03$

$0.82847 \mathrm{E}-03$

$0.72863 \mathrm{E}-03$

$0.91032 \mathrm{E}-02$

$0.74434 \mathrm{E}-02$

$\begin{array}{ll}0.48071 \mathrm{E}-02 & 0.53301 \mathrm{E}-03 \\ 0.38761 \mathrm{E}-03\end{array}$

$0.38735 \mathrm{E}-02 \quad 0.38003 \mathrm{E}-03$

$0.31628 \mathrm{E}-02 \quad 0.32583 \mathrm{E}-03$

$0.25904 \mathrm{E}-02 \quad 0.27904 \mathrm{E}-03$

$0.22060 \mathrm{E}-02 \quad 0.24729 \mathrm{E}-03$

$0.19257 \mathrm{E}-02 \quad 0.22225 \mathrm{E}-03$

$0.17648 \mathrm{E}-02 \quad 0.20786 \mathrm{E}-03$

$0.73067 \mathrm{E}+01$

$0.71518 \mathrm{E}+01$

$0.59469 \mathrm{E}+01$

$0.44397 \mathrm{E}+01$

$0.31249 \mathrm{E}+01$

$0.20819 \mathrm{E}+01$

$0.13742 \mathrm{E}+01$

$0.89516 \mathrm{E}+00$

$0.59697 \mathrm{E}+00$

$0.39879 \mathrm{E}+00$

$0.27285 \mathrm{E}+00$

$0.18725 E+00$

$0.13168 \mathrm{E}+00$

$0.96460 \mathrm{E}-01$

$0.72108 \mathrm{E}-01$

$0.58285 \mathrm{E}-01$

$0.50351 \mathrm{E}-01$

$0.48550 \mathrm{E}-01$

$0.49780 \mathrm{E}-01$

$0.50238 E+01$

$0.48591 \mathrm{E}+01$

$0.44012 E+01$

$0.37444 E+01$

$0.30069 \mathrm{E}+01$

$0.22944 E+01$

$0.16773 \mathrm{E}+01$

$0.11860 \mathrm{E}+01$

$0.81970 \mathrm{E}+00$

$0.56001 \mathrm{E}+00$

$0.38259 \mathrm{E}+00$

$0.26443 \mathrm{E}+00$

$0.18697 \mathrm{E}+00$

$0.13669 \mathrm{E}+00$

$0.10430 \mathrm{E}+00$

$0.83756 \mathrm{E}-01$

$0.71256 \mathrm{E}-01$

$0.64541 \mathrm{E}-01$

$0.62425 \mathrm{E}-01$

$0.10955 \mathrm{E}+00$

$0.84793 \mathrm{E}-02$

$0.14209 \mathrm{E}+02$

Angle
integr.

$0.10368 \mathrm{E}+01$

$0.84793 \mathrm{E}-0$.

Continuum cross section for E-out $=30.00 \mathrm{MeV}$

$\begin{array}{rccc}\text { Angle } & 1 \text {-step } & 2 \text {-step } & 3 \text {-step } \\ & & & \\ 0.0 & 0.17579 \mathrm{E}+01 & 0.16591 \mathrm{E}+01 & 0.35004 \mathrm{E}+00 \\ 10.0 & 0.16850 \mathrm{E}+01 & 0.16083 \mathrm{E}+01 & 0.34310 \mathrm{E}+00 \\ 20.0 & 0.14331 \mathrm{E}+01 & 0.14904 \mathrm{E}+01 & 0.32658 \mathrm{E}+00\end{array}$

4-step
$0.39436 E-01$
$0.38873 E-01$
$0.37566 E-01$

5-step
$0.31838 \mathrm{E}-02$
$0.31493 \mathrm{E}-02$

Total

Kalbach

$0.38097 \mathrm{E}+01$

$.36784 \mathrm{E}+01$

$0.31152 \mathrm{E}+01$

$0.28281 E+01$ 


$\begin{array}{rr}30.0 & 0.11674 \mathrm{E}+01 \\ 40.0 & 0.88982 \mathrm{E}+00 \\ 50.0 & 0.60432 \mathrm{E}+00 \\ 60.0 & 0.39830 \mathrm{E}+00 \\ 70.0 & 0.24589 \mathrm{E}+00 \\ 80.0 & 0.15536 \mathrm{E}+00 \\ 90.0 & 0.10238 \mathrm{E}+00 \\ 100.0 & 0.68832 \mathrm{E}-01 \\ 110.0 & 0.49681 \mathrm{E}-01 \\ 120.0 & 0.36936 \mathrm{E}-01 \\ 130.0 & 0.28571 \mathrm{E}-01 \\ 140.0 & 0.24205 \mathrm{E}-01 \\ 150.0 & 0.22824 \mathrm{E}-01 \\ 160.0 & 0.23748 \mathrm{E}-01 \\ 170.0 & 0.27680 \mathrm{E}-01 \\ 180.0 & 0.30455 \mathrm{E}-01 \\ & \\ & \end{array}$

$0.13268 E+01$
$0.11325 E+01$
$0.91493 E+00$
$0.71754 E+00$
$0.54878 E+00$
$0.40811 E+00$
$0.30104 E+00$
$0.22118 E+00$
$0.16177 E+00$
$0.12082 E+00$
$0.93585 E-01$
$0.75445 E-01$
$0.64408 E-01$
$0.57828 E-01$
$0.54394 E-01$
$0.52987 E-01$

$0.30382 \mathrm{E}+00$

$0.27338 \mathrm{E}+00$

$0.23781 E+00$

$0.20265 \mathrm{E}+00$

$0.16928 \mathrm{E}+00$

$0.13906 \mathrm{E}+00$

$0.11274 E+00$

$0.90535 \mathrm{E}-01$

$0.72052 \mathrm{E}-01$

$0.57904 \mathrm{E}-01$

$0.47428 \mathrm{E}-01$

$0.39480 \mathrm{E}-01$

$0.34007 \mathrm{E}-01$

$0.30303 E-01$

$0.28165 \mathrm{E}-01$

$0.27279 \mathrm{E}-01$

$0.35807 \mathrm{E}-01$

$0.33223 \mathrm{E}-01$

$0.29716 \mathrm{E}-02$

$0.28369 \mathrm{E}+01$

$0.23318 \mathrm{E}+01$

$0.30172 \mathrm{E}-01$

$0.26951 \mathrm{E}-01$

$0.23696 \mathrm{E}-01$

$0.20658 \mathrm{E}-01$

$0.17795 \mathrm{E}-01$

$0.17899 \mathrm{E}+01$

$0.13479 \mathrm{E}+01$

$0.98984 E+00$

$0.72517 \mathrm{E}+00$

$0.53574 E+00$

$0.39730 \mathrm{E}+00$

$0.15171 \mathrm{E}-01$

$0.12817 \mathrm{E}-01$

$0.10931 E-01$

$0.94274 \mathrm{E}-02$

$0.81863 \mathrm{E}-02$

$0.73037 \mathrm{E}-02$

$0.66575 \mathrm{E}-02$

$0.6277 \mathrm{OE}-02$

$0.24122 E-02$

$0.19851 \mathrm{E}-02$

$0.17795 \mathrm{E}-02$

$0.15801 \mathrm{E}-02$

$0.13916 \mathrm{E}-02$

$0.12382 \mathrm{E}-02$

$0.11103 E-02$

$0.91818 \mathrm{E}-03$

$0.85547 \mathrm{E}-03$

$0.81856 \mathrm{E}-03$

$0.29771 \mathrm{E}+00$

$0.22783 \mathrm{E}+00$

$0.18012 \mathrm{E}+00$

$0.14831 \mathrm{E}+00$

$0.12946 \mathrm{E}+00$

$0.11939 \mathrm{E}+00$

$0.11733 \mathrm{E}+00$

$0.11765 E+00$

$0.25131 \mathrm{E}+01$

$0.21409 \mathrm{E}+01$

$0.17571 \mathrm{E}+01$

$0.13976 \mathrm{E}+01$

$0.10849 \mathrm{E}+01$

$0.82827 \mathrm{E}+00$

$0.62702 E+00$

$0.47466 \mathrm{E}+00$

$0.36238 \mathrm{E}+00$

$0.28131 \mathrm{E}+00$

$0.22375 E+00$

$0.18364 \mathrm{E}+00$

$0.15644 \mathrm{E}+00$

$0.13902 \mathrm{E}+00$

$0.12932 \mathrm{E}+00$

$0.17237 \mathrm{E}+01$

$0.24382 E+\infty 0$

$0.23207 \mathrm{E}-01$

$0.11715 E+02$

integr.

Continuum cross section for E-out= $20.00 \mathrm{MeV}$

Angle 1-step 2-step 3-step

$0.0 \quad 0.60265 \mathrm{E}+00$

$0.67911 \mathrm{E}+00$

$0.52216 \mathrm{E}+00$

$0.44948 E+00$

$0.36289 \mathrm{E}+00$

$0.27396 \mathrm{E}+00$

$0.19858 \mathrm{E}+\infty 0$

$0.13778 E+\infty 0$

$0.91641 \mathrm{E}-01$

$0.60813 \mathrm{E}-01$

$0.41367 \mathrm{E}-01$

$0.29633 \mathrm{E}-01$

$0.22648 \mathrm{E}-01$

$0.18540 \mathrm{E}-01$

$0.17167 \mathrm{E}-01$

$0.17673 \mathrm{E}-01$

$0.20854 E-01$

$0.27548 \mathrm{E}-01$

$0.31581 \mathrm{E}-01$

$0.10562 \mathrm{E}+01$

$0.10297 \mathrm{E}+01$

$0.96616 \mathrm{E}+00$

$0.87737 \mathrm{E}+00$

$0.77089 \mathrm{E}+00$

$0.64911 \mathrm{E}+00$

$0.53554 \mathrm{E}+00$

$0.43357 \mathrm{E}+00$

$0.34489 \mathrm{E}+00$

$0.27365 \mathrm{E}+00$

$0.21733 \mathrm{E}+00$

$0.17240 \mathrm{E}+\infty$

$0.14033 \mathrm{E}+00$

$0.11903 \mathrm{E}+00$

$0.10547 \mathrm{E}+00$

$0.97910 \mathrm{E}-01$

$0.93966 \mathrm{E}-01$

$0.92790 \mathrm{E}-01$

$0.92374 E-01$

$0.46007 \mathrm{E}+01$

$0.32774 \mathrm{E}+00$

$0.32247 \mathrm{E}+00$

$0.30985 E+00$

0. 29238E +00

$0.26915 \mathrm{E}+00$

$0.24136 \mathrm{E}+00$

$0.21334 \mathrm{E}+00$

$0.18551 E+00$

$0.15985 \mathrm{E}+00$

$0.13694 \mathrm{E}+00$

$0.11706 \mathrm{E}+00$

$0.99517 \mathrm{E}-01$

$0.85806 \mathrm{E}-01$

$0.75514 \mathrm{E}-01$

$0.67462 \mathrm{E}-01$

$0.61802 E-01$

$0.57890 \mathrm{E}-0.1$

$0.55755 \mathrm{E}-01$

$0.54813 E-01$

$0.19406 \mathrm{E}+01$ 4-step

$0.48914 \mathrm{E}-01$

$0.48356 \mathrm{E}-01$

$0.47070 \mathrm{E}-01$

$0.45332 \mathrm{E}-01$

$0.42858 \mathrm{E}-01$

$0.39851 \mathrm{E}-01$

$0.36630 \mathrm{E}-01$

$0.33227 \mathrm{E}-01$

$0.30048 \mathrm{E}-01$

$0.27004 \mathrm{E}-01$

$0.24184 E-01$

$0.21512 E-01$

$0.19358 \mathrm{E}-01$

$0.17623 E-01$

$0.16136 E-01$

$0.15050 \mathrm{E}-01$

$0.14244 E-01$

$0.13784 \mathrm{E}-01$

$0.13587 \mathrm{E}-01$

$0.35654 \mathrm{E}+00$ 5-step

$0.48754 \mathrm{E}-02$

$0.48337 \mathrm{E}-02$

$0.47420 \mathrm{E}-02$

$0.46225 \mathrm{E}-02$

$0.44426 \mathrm{E}-02$

$0.42229 \mathrm{E}-02$

$0.39758 \mathrm{E}-02$

$0.37043 \mathrm{E}-02$

$0.34534 \mathrm{E}-02$

$0.32006 \mathrm{E}-02$

$0.29560 \mathrm{E}-02$

$0.27123 E-02$

$0.25158 \mathrm{E}-02$

$0.23505 \mathrm{E}-02$

$0.22002 \mathrm{E}-02$

$0.20895 \mathrm{E}-02$

$0.20030 \mathrm{E}-02$

$0.19537 \varepsilon-02$

$0.19335 E-02$

$0.41022 \mathrm{E}-01$

integr.

Angle integrated cross section

\begin{tabular}{|c|c|c|c|c|c|c|}
\hline Energy & 1 -step & 2-step & 3-step & 4-step & 5-step & Total \\
\hline 20.00 & $0.16923 \mathrm{E}+01$ & $0,46007 \mathrm{E}+01$ & $0.19406 E+01$ & $0.35654 \mathrm{E}+00$ & $0.41022 \mathrm{E}-01$ & $0.86312 E+01$ \\
\hline 30.00 & $0.38005 E+01$ & $0.59240 E+01$ & $0.17237 \mathrm{E}+01$ & $0.24382 \mathrm{E}+00$ & $0.23207 \mathrm{E}-01$ & $0.11715 \mathrm{E}+02$ \\
\hline 40.00 & $0.76358 \mathrm{~B}+01$ & $0.54179 \mathrm{E}+01$ & $0.10368 \mathrm{E}+01$ & $0.10955 \mathrm{E}+00$ & $0.84793 \mathrm{E}-02$ & $0.14209 \mathrm{E}+02$ \\
\hline 50.00 & $0.10272 E+02$ & $0.36812 E+01$ & $0.43695 \mathrm{E}+00$ & $0.33259 \mathrm{E}-01$ & $0.20654 \mathrm{E}-02$ & $0.14425 \mathrm{E}+02$ \\
\hline 60.00 & $0.85218 \mathrm{E}+01$ & $0.12963 \mathrm{E}+01$ & $0.84448 E-01$ & $0.44990 \mathrm{E}-02$ & $0.21858 \mathrm{E}-03$ & $0.99073 \mathrm{E}+01$ \\
\hline 70.00 & $0.47395 \mathrm{E}+01$ & $0.17821 E+00$ & $0.67962 \mathrm{E}-02$ & $0.26053 \mathrm{E}-03$ & $0.10020 \mathrm{E}-04$ & $0.49248 \mathrm{E}+01$ \\
\hline $\begin{array}{l}\text { Energy } \\
\text { integr. }\end{array}$ & $0,36418 E+03$ & $0.19054 \mathrm{E}+03$ & $0.42843 \mathrm{E}+02$ & $0.56467 \mathrm{E}+01$ & $0.53183 E+00$ & $0.60374 E+03$ \\
\hline
\end{tabular}

Total

$0.20404 E+01$

$0.19844 E+01$

$0.18600 \mathrm{E}+0$

$0.16692 \mathrm{E}+01$

$0.14502 \mathrm{E}+01$

$0.12085 \mathrm{E}+01$

$0.98806 \mathrm{E}+00$

$0.79378 \mathrm{E}+00$

$0.62989 \mathrm{E}+\infty 0$

$0.50161 \mathrm{E}+00$

$0.40290 \mathrm{E}+00$

$0.32577 \mathrm{E}+00$

$0.27066 \mathrm{E}+00$

$0.23306 \mathrm{E}+00$

$0.20844 \mathrm{E}+00$

$0.19452 E+\infty 0$

$0.18996 \mathrm{E}+00$

$0.19183=+00$

$0.19429 \mathrm{E}+00$

$0.86312 \mathrm{E}+01$
Kalbach

0. $17063 \mathrm{E}+01$

$0.16779 \mathrm{E}+01$

$0.15962 \mathrm{E}+01$

$0.14713 E+01$

$0.13172 E+01$

$0.11493 E+01$

$0.98141 E+\infty 0$

$0.82406 \mathrm{E}+\infty 0$

$0.68402 \mathrm{E}+00$

$0.56448 E+00$

$0.46583 \mathrm{E}+00$

$0.38667 \mathrm{E}+00$

$0.32468 \mathrm{E}+00$

$0.27724 \mathrm{E}+00$

$0.24190 \mathrm{E}+00$

$0.21658 \mathrm{E}+\infty 0$

$0.19963 \mathrm{E}+00$

$0.18991 \mathrm{E}+00$

$0.18674 \mathrm{E}+00$ 